\title{
Chapter 17 \\ Internal Radiation Dose of KURRI Volunteers Working at Evacuation Shelters After TEPCO's Fukushima Daiichi Nuclear Power Plant Accident
}

\author{
Yuko Kinashi, Kouta Kurihara, Keiko Fujiwara, Eiko Kakihana, \\ Tomohiro Miyake, Tomoyuki Takahashi, Tatsuya Yamada, Hiroshi Yashima, \\ Hidehito Nakamura, Kenichi Okamoto, and Sentaro Takahashi
}

\begin{abstract}
We report the radiation doses encountered by 59 Kyoto University Research Reactor Institute (KURRI) staff members who had been dispatched to screen refugees for radiation at emergency evacuation sites $45-80 \mathrm{~km}$ from the Tokyo Electric Power Co. (TEPCO) Fukushima Daiichi Nuclear Power Plant. From March 20 to April 30, 2011, 42 members were dispatched to the emergency evacuation sites located $45-80 \mathrm{~km}$ from the power plant to examine the radioactive contamination affecting refugees. Continuously, from May 10 to May 23, 2011, 17 members were dispatched to Fukushima Prefecture to establish the Kyoto University Radiation Mapping (KURAMA) system. Body burdens of radioactive nuclides were estimated using a whole-body counter. The first team dispatched showed $1,300-1,929 \mathrm{~Bq}$ internal radiation activity from cesium (including ${ }^{137} \mathrm{Cs}$ and ${ }^{134} \mathrm{Cs}$ ) and $48-118 \mathrm{~Bq}^{131} \mathrm{I}$. The internal doses of four members of the first team were estimated to be $24-39 \mu \mathrm{Sv}$. The doses from internal exposure were almost similar to the cumulative external doses for the dispatch period (March 20-22, 2011) The external radiation doses of members dispatched after the second team had decreased from one third to less than one tenth of the external doses of the first dispatched team. The internal radiation doses of 55 members after the second team showed that 51 cases were undetectable and 4 cases showed doses of $2-15 \mu \mathrm{Sv}$.
\end{abstract}

Keywords Cesium-134 • Cesium-137 • Internal radiation • Iodine-131 • Wholebody counter

\footnotetext{
Y. Kinashi $(\bowtie) \bullet$ K. Kurihara $\bullet$ K. Fujiwara $\bullet$ E. Kakihana $\bullet$ T. Miyake $\bullet$ T. Takahashi

- T. Yamada $\bullet$ H. Yashima $\bullet$ H. Nakamura $\bullet$ K. Okamoto $\bullet$ S. Takahashi

Research Reactor Institute, Kyoto University, 2-1010, Asashiro-nishi, Kumatori-cho, Sennan-gun, Osaka 590-0494, Japan

e-mail: kinashi@rri.kyoto-u.ac.jp
} 


\subsection{Background}

On March 11, 2011, an earthquake and tsunami struck the Tohoku area of Japan, causing serious damage to the Tokyo Electric Power Co. (TEPCO) Fukushima Daiichi Nuclear Power Plant, and a significant amount of radionuclides was released into the surrounding environment (Fuyuno 2011; Butler 2011). The radioactive plume spread over Fukushima Prefecture toward the end of March 2011.

Fifty-nine members as the total number of man-teams of the Kyoto University Research Reactor Institute (KURRI) had been dispatched to the emergency evacuation shelters in Fukushima Prefecture 45-80 km from the power plant to help the local governments in screening the radioactivity level of refugees. From March 20 to April 30, 2011, 42 members in teams consisting of 2-4 staff were dispatched 13 times to nine emergency evacuation shelters. From May 10 to May 23, 2011, 17 members in teams consisting of 2-5 staff were dispatched six times to Fukushima Prefecture to establish the Kyoto University Radiation Mapping (KURAMA) system. All screening teams, especially the earlier one, risked internal radiation exposure because of the radioactivity in the environment.

Two volunteers of the initial team who had a high external and internal radiation dose were followed up 513 days after the first dispatch.

\subsection{Methods}

The external radiation dose for each staff member was measured using a personal dosimeter (ADM-112; Hitachi-Aloka Medical). For the internal radiation doses, body counters of radioactivity were determined using a whole-body counter consisting of an iron room, the 8 in. $\varphi \times 4$ in. $t \mathrm{NaI}(\mathrm{Tl})$ with four photomultiplier tubes (Fuji Denki), and a digital multichannel analyzer (MCA7600; Seiko EG\&G) (Fig. 17.1). Body content of radioactivity was determined for $10 \mathrm{~min}$ using the whole-body counter, 3-4 days after returning from the dispatch. A spectral stripping method was used for the pulse amplitude analysis of ${ }^{131} \mathrm{I},{ }^{134} \mathrm{Cs}$, and ${ }^{137} \mathrm{Cs}$ with the whole-body counter. The whole-body counter was calibrated using the human acryl phantom filled with $\mathrm{KCl}$ solution containing $40 \mathrm{kBq}{ }^{40} \mathrm{~K}$. The conversion from the measured radioactivity in the body to the committed effective dose by internal exposure was evaluated with the MONDAL 3 (monitoring to dose calculation ver. 3) from the National Institute of Radiological Science (NIRS). MONDAL is a userfriendly tool for internal dose calculation based on the ICRP biokinetic models, by which the committed effective dose can be calculated from the whole-body counter results (Ishigure 2004). Volunteers stayed in the local hotel $100 \mathrm{~km}$ from TEPCO's plant. They consumed served food without radioactive contamination during the screening work. The intake route of radioactive particles was considered to be inhalation. All the radioactivities were assumed to be taken by inhalation of $1.0-\mu \mathrm{m}$ aerodynamic diameter particles in this calculation. The effective doses were calculated using the last working day as the acute inhalation of the radioactive particles. 

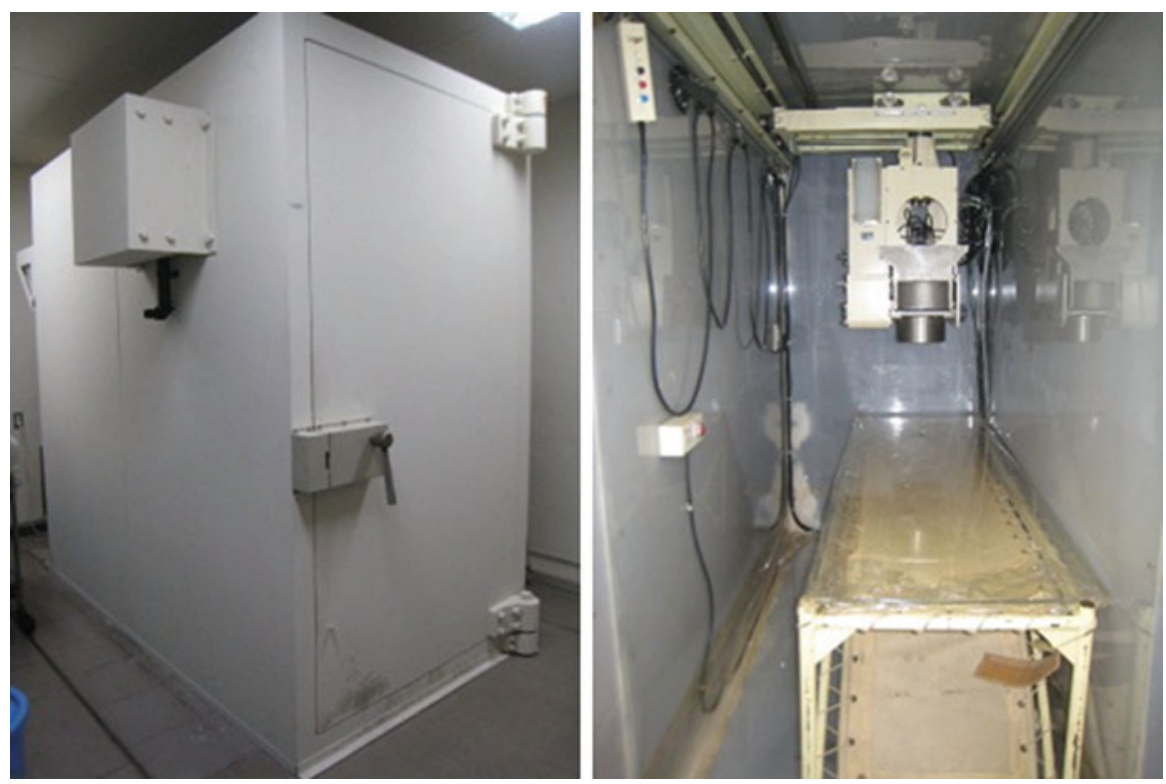

Fig. 17.1 KURRI whole-body counter. Left: exterior. The iron walls, ceiling, and floor of the iron room are $20 \mathrm{~cm}$ thick, with the inner surfaces lined with 3-mm Pb sheet. Right: Interior. The 8 in. $\varphi \times 4$ in. $t \mathrm{NaI}(\mathrm{Tl})$ crystal scintillation counter and four photomultiplier tubes are $40 \mathrm{~cm}$ above the bed

\subsection{Results}

\subsubsection{Initial Measurement of External Radiation and Internal Radiation Doses of Volunteers}

The dispatch period, working place, and distance from TEPCO's plant, air dose rate, and external radiation doses of KURRI volunteers are listed in Table 17.1. The external radiation dose shows the 24-h doses for each volunteer using a personal dosimeter. As shown in Table 17.1, the data of screening teams 2-13, it is difficult to estimate the external exposure dose from the ambient dose rate because dose rate differs by place.

The internal radiation doses of ${ }^{131} \mathrm{I}$ and ${ }^{134} \mathrm{Cs}+{ }^{137} \mathrm{Cs}$ are listed in Table 17.2. The spectral stripping method for the $\mathrm{NaI}$ whole-body counter cannot distinguish between ${ }^{134} \mathrm{Cs}$ and ${ }^{137} \mathrm{Cs}$. We estimated that the ratio of ${ }^{134} \mathrm{Cs}-{ }^{137} \mathrm{Cs}$ was $1: 1$, on the basis of the data from the measurements of the protecting masks using a germanium detector (Table 17.3). Four volunteers in Screening Team 1 showed 1,929, 1,816, 1,469 , and $1,300 \mathrm{~Bq}$ of radiocesium $\left({ }^{137} \mathrm{Cs}\right.$ and $\left.{ }^{134} \mathrm{Cs}\right)$ and $118,72,52$, and $48 \mathrm{~Bq}$ of ${ }^{131} \mathrm{I}$, respectively. The internal doses of radiocesium were estimated to be $28,26,21$, and $19 \mu \mathrm{Sv}$, and the internal doses of radioiodine were estimated to be $11,7,5$, and $5 \mu \mathrm{Sv}$, respectively. 


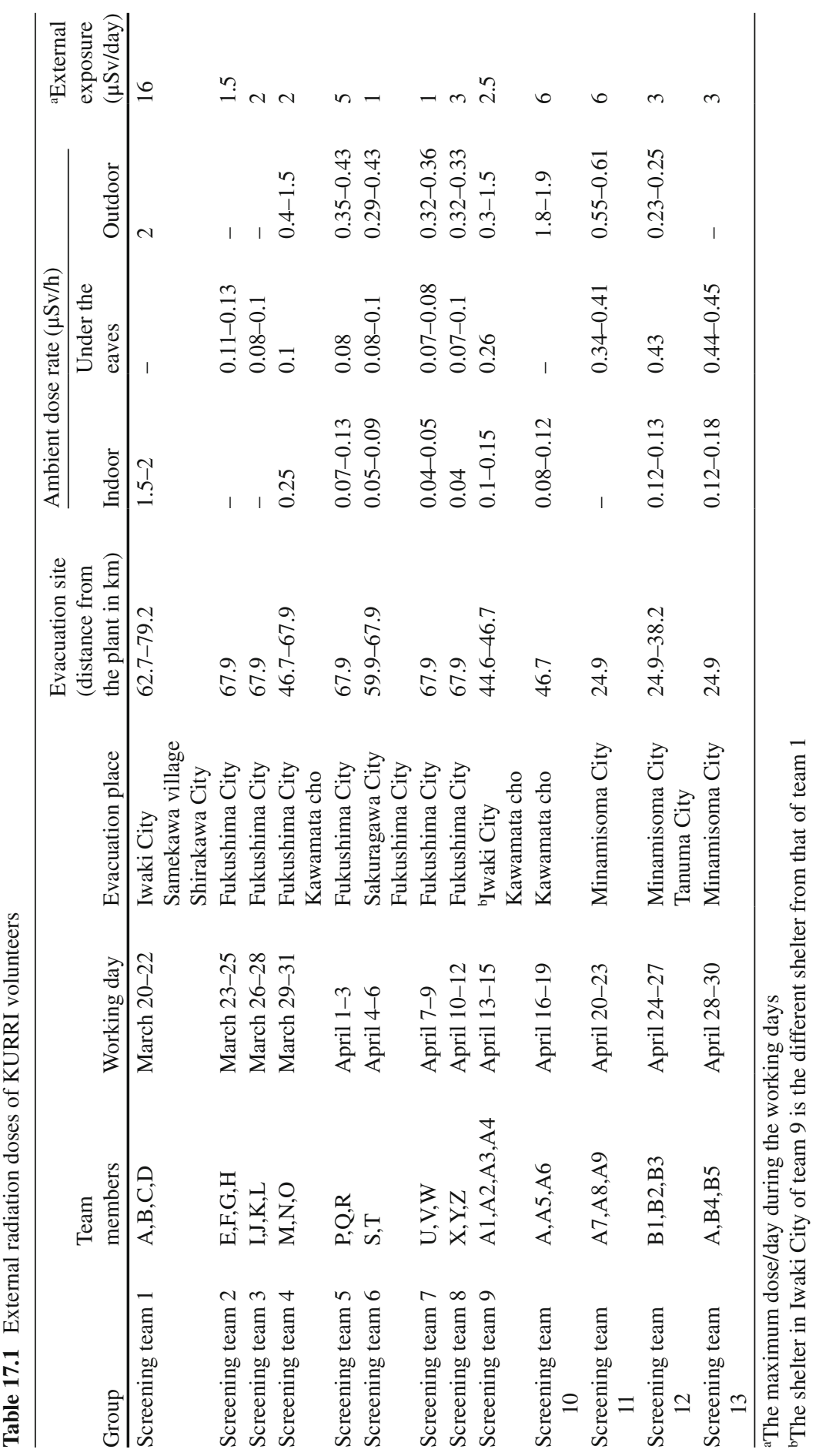


Table 17.2 Internal radiation doses estimated with human counter at KURRI

\begin{tabular}{|c|c|c|c|c|c|}
\hline \multirow[b]{2}{*}{ Group } & \multirow{2}{*}{$\begin{array}{l}\text { Volunteer's } \\
\text { number }\end{array}$} & \multicolumn{2}{|c|}{ 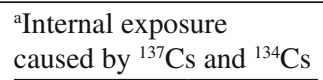 } & \multicolumn{2}{|c|}{$\begin{array}{l}\text { anternal exposure } \\
\text { caused by }{ }^{131} \mathrm{I}\end{array}$} \\
\hline & & $(\mathrm{Bq})$ & $(\mu \mathrm{Sv})$ & $(\mathrm{Bq})$ & $(\mu \mathrm{Sv})$ \\
\hline Screening team 1 & 4 & 1,929 & 28 & 118 & 11 \\
\hline Screening team 2 & 4 & ${ }^{b} \mathrm{ND}$ & 0 & ND & 0 \\
\hline Screening team 3 & 4 & ND & 0 & ND & 0 \\
\hline Screening team 4 & 3 & 688 & 11 & 27 & 4 \\
\hline Screening team 5 & 3 & ND & 0 & ND & 0 \\
\hline Screening team 6 & 2 & 593 & 9 & ND & 0 \\
\hline Screening team 7 & 3 & $\mathrm{ND}$ & 0 & 18 & 2 \\
\hline Screening team 8 & 3 & ND & 0 & ND & 0 \\
\hline Screening team 9 & 4 & ND & 0 & ND & 0 \\
\hline Screening Team 10 & 3 & ND & 0 & ND & 0 \\
\hline Screening Team 11 & 3 & ND & 0 & ND & 0 \\
\hline Screening Team 12 & 3 & ND & 0 & ND & 0 \\
\hline Screening Team 13 & 3 & $\mathrm{ND}$ & 0 & ND & 0 \\
\hline KURAMA Team 1 & 4 & ND & 0 & ND & 0 \\
\hline KURAMA Team 2 & 2 & ND & 0 & ND & 0 \\
\hline KURAMA Team 3 & 2 & $\mathrm{ND}$ & 0 & ND & 0 \\
\hline KURAMA Team 4 & 2 & 594 & 9 & ND & 0 \\
\hline KURAMA Team 5 & 2 & $\mathrm{ND}$ & 0 & ND & 0 \\
\hline KURAMA Team 6 & 5 & $\mathrm{ND}$ & 0 & ND & 0 \\
\hline
\end{tabular}

${ }^{a}$ The maximum internal dose of the each group

${ }^{\mathrm{b}} N D$ not detected

Table 17.3 The cesium analysis of the protecting masks by a germanium semiconductor detector

\begin{tabular}{lllll}
\hline Dispatched date & No of masks & Cs-134 (Bq/mask) & Cs-136 (Bq/mask) & Cs-137 (Bq/mask) \\
\hline $2011.3 .20-3.22$ & 11 & 2.2 & 0.2 & 2.5 \\
$2011.3 .23-3.25$ & 12 & 0.2 & 0 & 0.3 \\
\hline
\end{tabular}

The doses from internal exposure were almost similar to the cumulative external doses for the dispatch period (March 20-22, 2011) when the radiation plumes following the explosions of Units 1 and 3 in TEPCO's Fukushima Daiichi nuclear plant had diffused over Fukushima City. The external radiation doses of the dispatched members after the second team decreased from one third to less than one tenth of the external doses of the first dispatched team. The internal radiation doses of 55 members after the second team was dispatched showed that 51 cases were undetectable and 4 cases showed doses of $2-15 \mu \mathrm{Sv}$.

\subsubsection{Follow-Up Data of Internal Doses for Two Volunteers}

Two volunteers belonging the initial team (Screening Team 1) showed a rather high level of internal radiation dose because they visited Fukushima Prefecture three or more times. Volunteer A visited four times and volunteer B visited three times. 


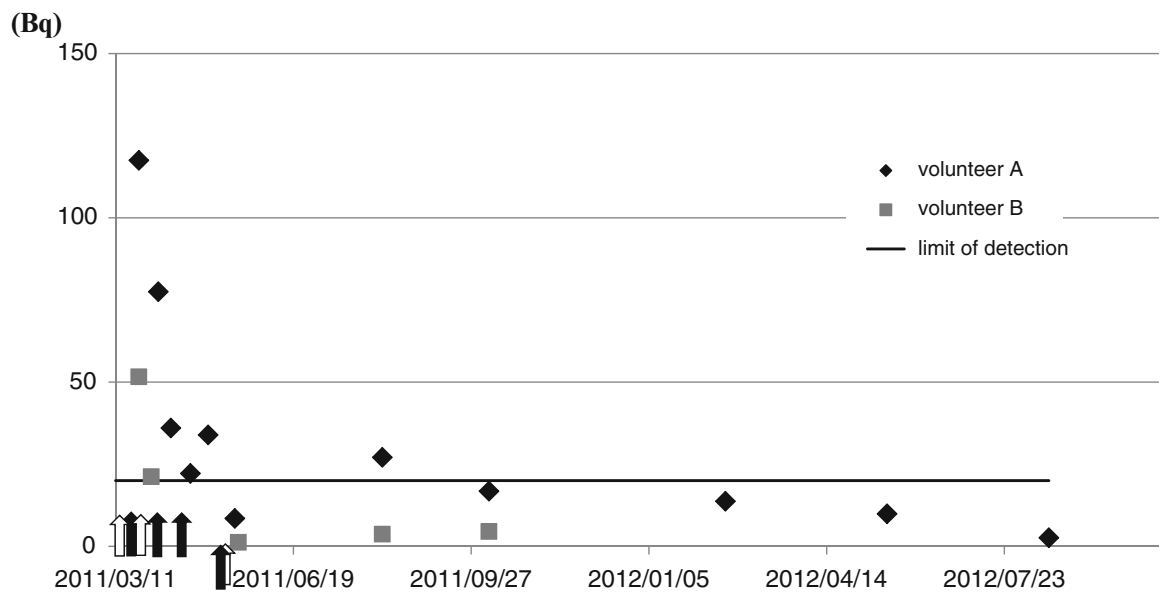

Fig. 17.2 Activity of ${ }^{131} \mathrm{I}$ measured by KURRI whole-body counter. Diamond symbols show the activity of ${ }^{131} \mathrm{I}$ of volunteer A. Volunteer A was dispatched joining in screening teams 1, 10, and 13 and KURAMA team 1. Black arrows show the dispatch period. Square symbols show the activity of ${ }^{131}$ I of volunteer B. Volunteer B had stayed in Sendai City on 3/11-3/13/2011. He dispatched joining in screening team 1 and KURAMA team 1. White arrows show the dispatched period

Volunteer A was dispatched joining in Screening Teams 1, 10, and 13 and KURAMA Team 1. Volunteer B had stayed in Sendai City on 3/11-3/13/2011. He joined Screening Team 1 and KURAMA Team 1. We followed up their internal radiation doses for 6 months, to $2012 / 08 / 17$. The activities of ${ }^{131} \mathrm{I}$ and ${ }^{134} \mathrm{Cs}+{ }^{137} \mathrm{Cs}$ are shown in Figs. 17.2 and 17.3, respectively. Iodine-131 of volunteer A was detected until 2011/05/02, and iodine-131 of volunteer B was detected until 2011/03/31. Cesium-137 and -134 of volunteer A was detected until 2012/05/18, and cesium-137 and -134 of volunteer B was detected until 2011/08/08.

\subsection{Discussion}

The staff stayed in Fukushima prefecture for 3-4 days per dispatch, working at evacuation sites during the day and staying at a hotel near Fukushima City at night. As shown in Tables 17.1 and 17.2, Screening Team 1 had the largest accumulated dose from external exposure and internal exposure caused by iodine and cesium. Their dispatched period was the earliest; moreover, they used only simple masks with casual clothing so as not to make the evacuees anxious, so there was little difference in protection from internal exposure between staff members and evacuees. On the basis of the internal radiation dose of the first dispatched team, we gave the next dispatched team a warning to protect against internal exposure. The decrease in internal radiation doses after the second team was dispatched is attributable to the warning statement to the dispatched staff of KURRI regarding protection against internal radiation. 


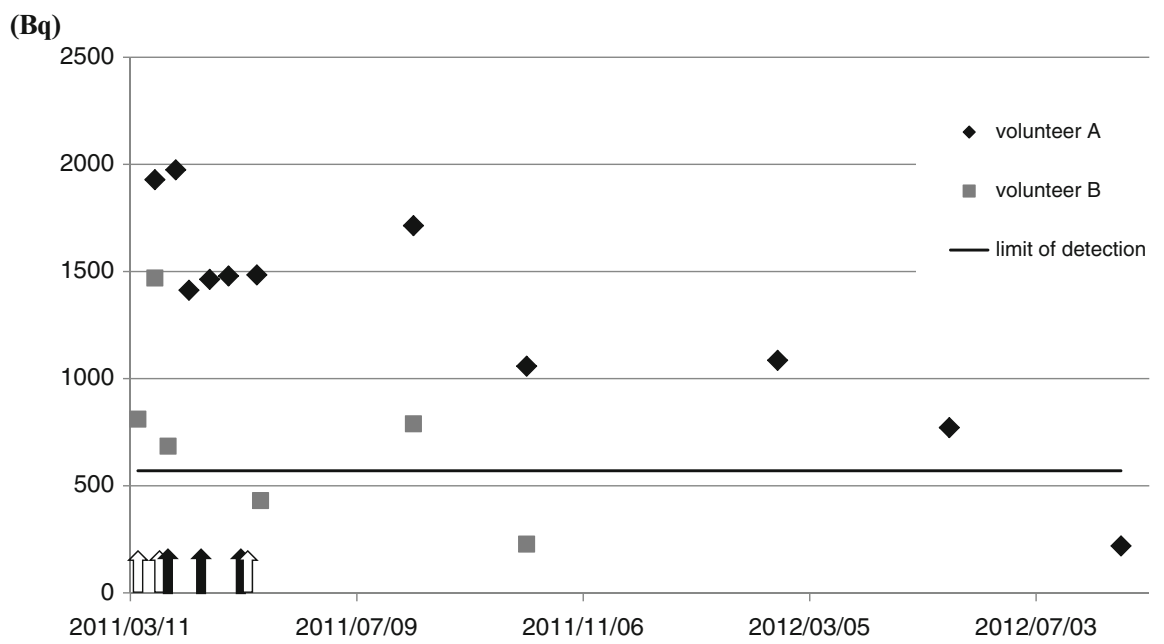

Fig. 17.3 The activity of ${ }^{134} \mathrm{Cs}+{ }^{137} \mathrm{Cs}$ measured by KURRI whole-body counter. Diamond symbols show the activity of ${ }^{134} \mathrm{Cs}+{ }^{137} \mathrm{Cs}$ of volunteer A. Square symbols show the activity of ${ }^{134} \mathrm{Cs}+{ }^{137} \mathrm{Cs}$ of volunteer B. Black arrows show the dispatched period of Volunteer A. White arrows show the dispatched period of Volunteer B

Between September 2011 and March 2012, the internal radiation exposure of cesium in the 9,498 evacuated residents of Minamisoma, located $23 \mathrm{~km}$ north of the TEPCO plant, was measured. It was reported that the committed effective doses were less than $1 \mathrm{mSv}$ in the 9,497 residents (Tsubokura 2012). We confirmed that internal exposure to cesium and iodine radiation soon after TEPCO's nuclear power plant accident was relatively low; that is, the largest effective dose was $39 \mu \mathrm{Sv}$ in the 59 dispatched KURRI volunteers. We are not aware of any published report on follow-up data of the internal exposure to cesium and iodine radiation measured with a whole-body counter in public after the early period following the TEPCO Fukushima Daiichi nuclear power plant accident.

The follow-up data of internal doses for two volunteers of the first dispatched team showed that the activity of iodine-131 was detected for 40 days in volunteer A and for 9 days in volunteer B after the last dispatch working day in Fukushima prefecture. Cesium-137 and -134 of volunteer A has been detected for 125 days and that in volunteer B for 56 days after the last dispatch working day in Fukushima.

The American Nuclear Society reported the initial measurements for residents who lived in areas associated with high doses of Fukushima Prefecture. Between June 27 and July 16 in 2011, the activities of cesium-134, cecium-137, and iodine-131 were measured in 122 residents by whole-body counter. Cesium-134 was detected $47.7 \%$ and cesium-137 at 29.4\%; the highest activity was 3,100 Bq of cesium-134 and $3,800 \mathrm{~Bq}$ of cesium-137. Iodine-131 was not detected. Based on this internal radiation measurement, the combined internal dose was less than $1 \mathrm{mSv}$ for residents (ANS Committee Report 2012). Similar to the internal radiation data of the residents living near the high-dose area in Fukushima, the activity of iodine-131 in 
two volunteers was not detected at the end of June 2011. The activities of cesium-137 and -134 of volunteer A and volunteer B on 2011/8/8 were measured as 1,714 and $789 \mathrm{~Bq}$, respectively. It is reported that the half-life in the human body of episodic ingestion of cesium was 100 days. When a human intakes cesium chronically, cesium accumulates in the body and reaches equilibrium (ICRP Publication 2009). The activities of cesium of volunteer A continued rather higher 138 days after the initial dispatch because he had visited Fukushima several times in the earlier period following the TEPCO Fukushima Daiichi nuclear power plant accident.

Open Access This article is distributed under the terms of the Creative Commons Attribution Noncommercial License which permits any noncommercial use, distribution, and reproduction in any medium, provided the original author(s) and source are credited.

\section{References}

1. Fuyuno I (2011) Quake shakes Japan's science. Nature 471:420

2. Butler D (2011) Radioactivity spreading in Japan. Nature 471:555-556

3. Ishigure $\mathrm{N}$ et al (2004) Development of software for internal dose calculation from bioassay measurements. Radiat Prot Dosim 109:235-242

4. Tsubokura M et al (2012) Internal radiation exposure after the Fukushima nuclear power plant disaster. JAMA 308:1621

5. American Nuclear Society (2012) A Report by The American Nuclear Society Special Committee on Fukushima, March 2012:15-18

6. ICRP Publication 111 (2009) Application of the commissions recommendations to the protection of people living in long-term contaminated areas after a nuclear accident or a radiation emergency: $20-22$ 